\title{
Study of Incentive Mechanism Innovation in Private Universities
}

\author{
Yang Guo ${ }^{1,}$, Kexin Zhang ${ }^{1, b}$ and Xin Dai ${ }^{1, c}$ \\ ${ }^{1}$ Jilin Huaqiao University of Foreign Languages, Changchun 130117, China

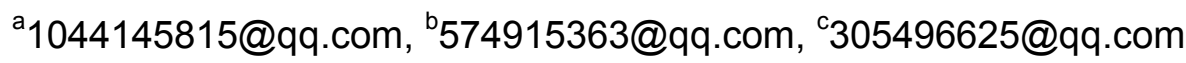

\begin{abstract}
Keywords: Private University; Incentive mechanism; Scientific research management
\end{abstract}
\begin{abstract}
The development of private universities needs the support of teacher, and the strong teacher is inseparable from the scientific research. Therefore, adjusting incentive mechanism of private universities timely is responsible for the whole teacher and an important means of the high-speed development of this university. The author discusses the innovation of scientific research management incentive mechanism from the material reward to the spiritual incentive, which has reference significance for the scientific management in future.
\end{abstract}

\section{Introduction}

The development of private universities needs the abundant faulty strength. Meanwhile, this process needs improving its own scientific research level. To a certain extent, high scientific research level depends on good scientific research management mode. Scientific research staff plays an important role in the work. Although private universities do not lie in the system, constructing their own scientific research team is essential, which is the development symbol of private universities. Private universities should consider the establishment of incentive mechanism management system, and completely stimulate the work passion of the scientific research administrators, which is the only way to the sustainable and healthy development of scientific research [1-2].

Private universities can introduce the core competence theory on business management in the scientific research management. XUAN Li-na discusses the core competence problem of the private universities from the development of teachers' scientific research ability, and explores how to identify the competitive advantage of scientific research and cultivates and improves the teachers' scientific research ability, which is beneficial to the sustainable development of private universities [3]. Scientific research management departments in the private universities should do a good job of scientific research management from the aspects of scientific research system innovation, management team construction. WU Li-ping analyzes the problems existing in the scientific research management work of the private universities in the new period and environment, and gives the corresponding measures [4]. Private universities can not simply adopt the scientific research management mode of public universities, and do some valuable work in the scientific research management idea and mechanism, improve scientific research management level and quality, in term of their own characteristics. Only in this way, Private universities can improve their core competitiveness, and keep sustainable competitive advantage [5]. WEN Chuan believes that private universities should deepen institutional reform mechanism to stimulate technological innovation and vitality, build talent teams, increase research funding to improve the scientific research conditions [6].

\section{Theory Summary of Incentive Mechanism.}

The Meaning of Incentive Mechanism. The so-called incentive mechanism is created by incentive, and a system promoting the organization development. Generally, it can divided into material incentive and spiritual incentive which have the complementary relationship. Managers often use this mechanism to improve organization efficiency and can get a good effect.

The Nature of Incentive Mechanism. Incentive mechanism is a stimulus, sometimes help to the organization development, but not always positive. While it occurs negative effect, the organization 
effectiveness is to be weakened. This is the encouragement and weakness of the incentive mechanism. Obviously, incentive mechanism can play the promoting and weakening roles.

\section{Analysis on the Situation of Scientific Research Management in Private Universities.}

Private universities has been developing rapidly in recent years, for instance, expanding scale, continuous rising professional level, and so on. But it is undeniable that the scientific research management of private universities is still very rough, the overall level of scientific research lags behind the key universities and colleges, and there are still many shortcomings. Fig .1 gives the analysis diagram of scientific research management in private universities.

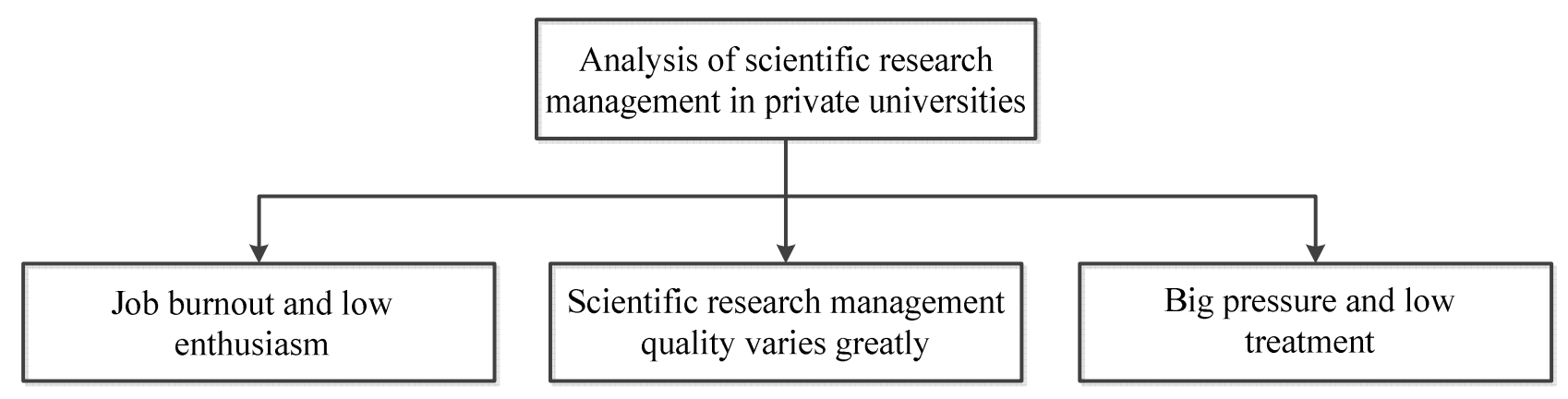

Figure 1. Finite Analysis diagram of scientific research management in private universities

Scientific Research Managers has the Job Burnout and Low Enthusiasm. The scientific research managers has not high research level, and they can not gain a certain level of subjects, of course, which has the position of private universities. Long-term inactive scientific research makes the related managers appear to be lazy, tired, and inimical sentiment. These negative effect hinders the development of the scientific research work.

The Quality of Scientific Research Management Varies Greatly. In the early period of establishment, private universities has low threshold of entry to the scientific research managers whose has relatively low degree. These staff have not the corresponding scientific research management knowledge they should have. When they meet the scientific research problems, they can not do with the matters well.

Scientific Research Managers has Big Pressure and Low Treatment. Scientific research manager in private universities have the low entry standards, and most of them are part-time, such as executive secretary, university counselors. These staff often has no extra bonuses, subsidies, benefits and authorized size. Some of the external staff often resign because of heavy workload and low wages. Then teaching secretaries have to undertake the extra work, which bring them more burden. As mentioned above, these teachers are lack of related scientific research management knowledge, making the entire work more confusing. Under the circumstances, private universities can not make the scientific research level improve, on the contrary, further lag behind. Scientific research management work every year should be reported to the university leaders for auditing to ensure that the related work gets recognition and not lags behind the key universities and colleges too much. But it is undeniable that scientific research work has the defection of extensive management, which makes scientific research management far away from professionalization. So the scientific research staff loses the confidence and the scientific research work is hindered.

\section{Application of Incentive Mechanism in the Scientific Research Management of Private Universities.}

China issued the High Education Law in 1998, putting forward valuing and strengthening the enhancement of running the university efficiency, studying how to improve the new human resources and integrating the existing human resources, and changing the status of private 
universities and colleges. In the process of the teachers' management change, private universities continuously introduce the human resource management approach of enterprises into high education. Private universities can start from the incentive mechanism, implement the appointment system, strengthen the teamwork, and realize the teachers' law of survival of fittest system. Incentive mechanism, as the driving force of stimulating people's goal and motivation, has the positive function for the scientific research management in the private universities. Fig .2 shows the application diagram of incentive mechanism in the scientific research management.

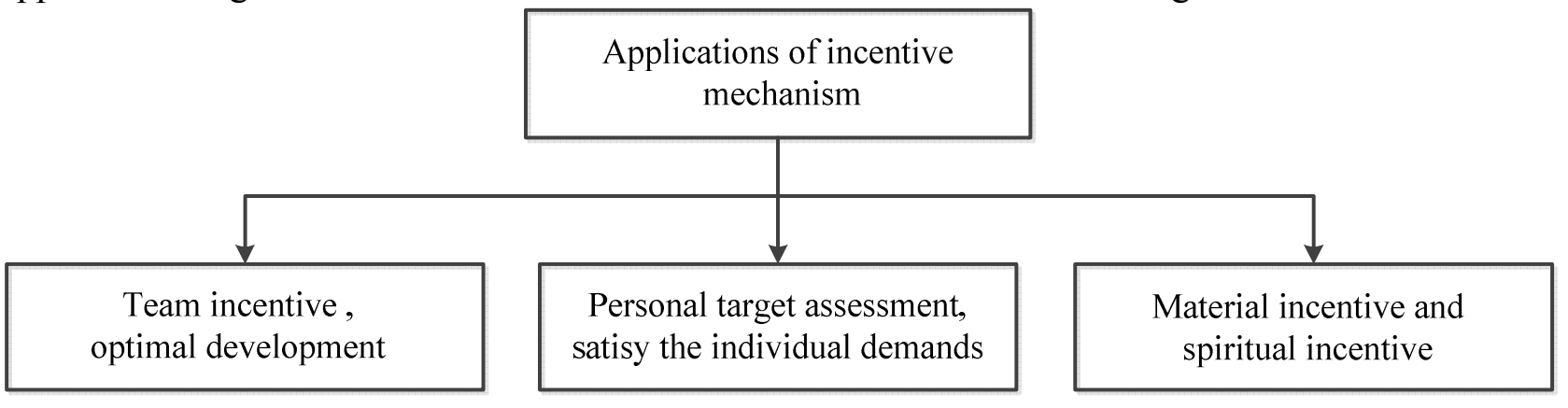

Figure 2. Finite Application diagram of incentive mechanism in the scientific research management

Implementing the Construction of Team Incentive, and Achieving the Optimal Development of Scientific Research Management. Private universities must pay close attention to scientific research management, and take the managers as an indispensable part of the university staff. The leaders should value the scientific research management, construct a qualified scientific research management team, audit the team members strictly, and encourage interaction of the members. Everyone puts forward their own views on the scientific research management, realizing fair and equitable competition. Private universities can implement performance evaluation system, and realize work output maximization of the team by virtue of individual rigorous assessment. In this way, scientific research management can be carried out reasonably and orderly, and team cohesiveness can be strengthened.

Strengthening the Personal Target Assessment, and Valuing the Individual Development Requirement. Incentive mechanism attaches importance to not only the team, but also the value of individual. The individual value being reflected and the individual realizing the flash point of self-worth in a team, is the starting point of the incentive mechanism. Therefore, long-term and short-term goals should be established so that individual work can be conducted in a step-by-step manner. After finishing a short-term goal, the staff can get a certain incentive, and then strive for the long-term goal further, which is vital to the development of scientific research management.

Implementing Material Incentive and Spiritual Incentive Optimizes Management System. Scientific research management work in private universities is done by specific person whose survival and development is inseparable from the material support from beginning to end. Therefore, in the implementation course of creating incentive, material incentive is indispensable, such as the growth in wage, the increase in welfare, the rise in allowance, and promotion in professional title. At the same time, spiritual incentive plays a supplementary role. After finishing a lot of labor, the scientific research managers can be promptly encouraged to comfort them. The staff can be full of enthusiasm to carry out the new work and meet the new struggle. The private universities should cite the advanced scientific research managers for their achievements timely.

\section{Conclusion.}

Scientific research management in private universities goes a long way. Private universities should stick to their own scientific research functions. In the process of training advanced talents, scientific research innovation has been continuously developed to pay the related fruits back to the society. 
Private universities with their own efforts adhere to scientific research and must get an abundant return. Of course, the national education sectors should also increase the support policies to promote the development of scientific research management in private universities.

\section{References}

[1] ZHANG Yu-bin: Improving the Quality of Scientific Research Management Staff to Promote the Enhancement of the Scientific Research in Private Colleges [J]. Industrial \& Science Tribune. Vol. 11, No. 22, pp. 246-247, Nov 2012.

[2] XUAN Li-na, ZHANG Jun-zong, HE Mao-bing: Reserch of Restricting Factors and Measures of Teachers' Scientific Research Ability in the Guangdong Private Colleges [J]. Heilongjiang Education. No. 3, pp. 89-90, Mar 2013.

[3] XUAN Li-na, HE Mao-bing and QIAN Jun-ping, etc: On the Cultivation of Teachers' Scientific Research Ability as the Core Competence in Private Colleges [J].Journal of Jiangxi Institute of Education. Vol. 33, No. 6, pp. 152-154, Dec 2012.

[4] WU Li-ping: Existing Problems and Countermeasures in the Non-governmental University Scientific Research Management under the Environment in the New Period [J]. Journal of Jiamusi Institute. No. 1, pp. 118, Jan 2015.

[5] XUAN Li-na, AN Xin, HE Mao-bing: Improve the Level of Scientific Research Management and Enhance Core Competitiveness of Private Universities [J]. Journal of Yan'an Vocational \& Technical Institute. Vol. 33, No. 1, pp. 16-17, 29, Feb 2013.

[6] WEN Chuan: Innovation Driven Strategy and Innovation of Scientific Research in Private Colleges[J]. Journal of Huanggang Polytechnic. Vol. 18, No. 1, pp. 35-37, Oct 2016. 